\title{
Effect of Flyash in Enhancing the Strength and Durability Characteristics of Foam Concrete
}

\author{
PL. Meyyappan, G. BharathBalji
}

\begin{abstract}
The major negative aspect of conventional concrete is having heavy density of $2400 \mathrm{~kg} / \mathrm{m}^{3}$ and the design of buildings especially high rise structures made up of these concrete leads to high cost, high man power and high lifting devices etc. As indicated in the past researches, there are several ways in reducing the dead weight of the members. Foam concrete is one of the types which is gaining attraction in nowadays and the research towards this concrete in improving the strength and durability characteristics has many wide openings in the research point of view. This paper made an attempt to investigate the strength and durability aspects of foam concrete. In order to produce the synthetic foam, the chemical such as toluene diisocyanate and polyol are used in the ratio of 1:1.1. In order to enhance the abovesaid properties, the mineral admixture of $25 \%$ of flyash is added in the foam concrete. Based on the experimental findings, it is understood that the foam concrete with flyash can able to achieve $85 \%$ of the strength and durability properties.
\end{abstract}

Keywords :Conventional concrete; Foam concrete, Flyash; Synthetic foam, Strength, Durability characteristics

\section{INTRODUCTION}

$$
\mathrm{T}
$$

he major drawback of the conventional concrete is very large density and due to that there might be a chance of uneconomical large sections in the design of structural elements. In the past literatures, it has been understood that there are several methods are available to reducing the density of concrete. They are light weight cellular concrete, low density cellular concrete, light weight aggregate concrete, autoclaved aerated concrete, aircrete, foam concrete etc. But the practical implementations of those methods are still in inception and still researches are carried out to improve the property of light weight / reduced density without compromising the strength and durability aspects. In order to reduce the density, the main thing to be implemented is to reduce / avoid the coarse aggregates in to the concrete which is called foam concrete. The wide range of advantages of the foam concrete are low density with high strength, high fluidity, well bonded body, self leveling and self compacting, reliability in life, resistance for climatic conditions, acoustic insulation and super fire resistant etc. Generally, the foam concrete is made up of cement, sand, water, foaming agent, mineral admixtures etc. The foaming agents are mainly classified into natural and synthetic. In natural foaming agent are made from coconut/palm fatty alcohols, corn, saponins, tannic extracts from leather industry and sulfite lye etc.

Revised Manuscript Received on December 05, 2019.

* Correspondence Author

PL. Meyyappan*, Civil department, Kalasalingam Academy of Research and Education, Krishnankoil, India. Email: meyyappan@klu.ac.in

G. BharathBalji, Civil department, Kalasalingam Academy of Research and Education, Krishnankoil, India. Email: bbalji07@gmail.com
Synthetic foaming agents are produced from chemical synthesis. In many past works, it has been noticed that optimized usage of foam are ranging from $15 \%$ to $20 \%$ and most preferred is synthetic foams due to the cheaper and easily producible. So an attempt is made to enhance the strength and durability properties of foam concrete using synthetic foaming agent along with the addition of mineral admixtures such as flyash. These foam concrete properties are compared with the control specimen made up of M30 grade concrete.

\section{MATERIAL USED}

The materials used in this study were ordinary Portland cement of 53 grade, fine aggregate, coarse aggregate, flyash and chemicals such as toluene diisocyanate and polyol to prepare the synthetic foams. As per the standards of IS:8112, the cement materials and as per IS: 383 , the aggregates are tested before mix preparation. Class ' $\mathrm{C}$ 'flyash collected from Tuticorin power plant are used in this experimental study.

\section{EXPERIMENTAL INVESTIGATION}

By using IS 10262 - 2009, the M30 grade was designed for the conventional concrete $(\mathrm{CC})$ and the mix ratio adapted for this experimental work is $1: 1.98: 2.74: 0.5$. Since there is no standard guidelines are available for the design of foam concrete, 1:3 mortar mix (FCM1) is taken for the study based on the past literature works along with foaming agents of $15 \%$. In the foam concrete mix (FCM1), $25 \%$ of cement is replaced with the mineral admixture of flyash and this foam concrete mix is designated as FCM2. The concrete mix proportion details for CC, FCM1 and FCM2 are shown in table 1. The preparation of conventional concrete is as usual dry mixture of concrete ingredients and calculated water is added slowly to prepare a wet mix. For the preparation of foam concrete, the synthetic foams are prepared by the reaction of two chemicals namely toluene diisocyanate and polyol in the ratio of $1: 1.1$. In order to prepare the FCM1 mix, all the ingredients were first mixed in the dry condition in the concrete mixer machine for about one minute. Then $75 \%$ of calculated amount of water was slowly added to the dry mix in machine to achieve a through wet mix mortar. Then the calculated quantity of prepared synthetic foam is added in the wet mortar. After that, the mixer machine is allowed to rotate for standard 4 minutes to get a uniform foam concrete mix (FCM1). In the same way, FCM2 mix is obtained by adding flyash in the dry state and repeats the same manner in the mixer machine. Table II indicates that cube specimen of $150 \mathrm{~mm} \mathrm{x}$ $150 \mathrm{~mm} \times 150 \mathrm{~mm}$ is taken for the compression test and water

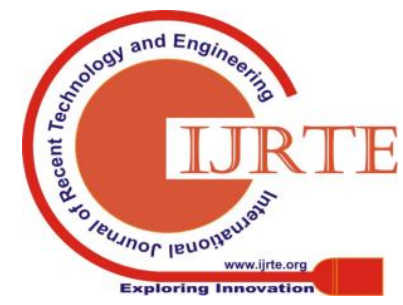


absorption test. Totally for those 2 tests, 36 cube specimens are casted and allowed to be cure under water for the period of 7 days and 28 days. For split tension test, 18 cylinders of size $100 \mathrm{~mm} \times 200 \mathrm{~mm}$ are casted for both 7 days and 28 days. For flexure test, 18 prism specimens of size $500 \mathrm{~mm} \mathrm{x}$ $100 \mathrm{~mm} \times 100 \mathrm{~mm}$ are casted against 7 days and 28 days.

Table- I: Concrete Mix proportion details

\begin{tabular}{|c|c|c|c|c|c|c|}
\hline نَّ & ن & 死 & 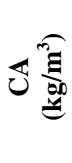 & 死 & 离莺 & छ \\
\hline $\mathrm{CC}$ & 394 & 787 & 1082 & - & 197 & - \\
\hline FCM1 & 670 & 2010 & - & - & 335 & 100.5 \\
\hline FCM2 & 502.5 & 2010 & - & 167.5 & 335 & 100.5 \\
\hline
\end{tabular}

Table- II: Specimen details

\begin{tabular}{|l|c|c|c|c|}
\hline & Description & $\begin{array}{c}\text { Compression } \\
\text { Test }\end{array}$ & $\begin{array}{c}\text { Split } \\
\text { Tension } \\
\text { Test }\end{array}$ & $\begin{array}{c}\text { Flexural } \\
\text { Test } \\
\text { Water } \\
\text { Absorption } \\
\text { Test }\end{array}$ \\
\hline CC & 3 & 3 & 3 & 3 \\
\hline FCM1 & 3 & 3 & 3 & 3 \\
\hline FCM2 & 3 & 3 & 3 & 3 \\
\hline Total & 9 & 9 & 9 & 9 \\
\hline \multicolumn{7}{|c|}{ Total Specimens - 36 each for 7 days and 28 days } \\
\hline
\end{tabular}

\section{RESULT AND DISCUSSIONS}

Table III shows the various test results such as slump, density, compressive strength, split tensile strength, flexural strength and water absorption test of the control specimen and foam concrete mix with and without flyash. The slump measured is $133 \mathrm{~mm}$ for the control specimen and $195 \mathrm{~mm}$ and $223 \mathrm{~mm}$ for the foam concrete mix 1 and 2 respectively. This slump test shows that the workability is changed from the medium range to higher range due to the presence of foam and flyash content. During the slump test, it is observed that the foam concrete is flowing uniformly in all sides under gravity. More over the presence of flyash, influences the workable rate to the further extent. This result is evidence that, to conclude the foam concrete is high workable one. The density of the conventional concrete (Control specimen) is $2301 \mathrm{~kg} / \mathrm{m}^{3}$. By introducing the FCM 1, the density is reduced to $14 \%$ and for FCM2 it is further reduced to $18 \%$. It's clearly indicating that, by using foam concrete, it is possible to reduce its self weight to around $20 \%$. Once the self weight is less to some extent, the economical section can be proceeding further in the design of the structures. By which the materials as well as cost is in the control. In the strength studies, it is observed from figure 1, the compressive strength of the control specimen is $33.17 \mathrm{~N} / \mathrm{mm}^{2}$. For foam concrete mixes FCM1 and FCM2, the compressive strength obtained is $20.49 \mathrm{~N} / \mathrm{mm}^{2}$ and $25.56 \mathrm{~N} / \mathrm{mm}^{2}$ respectively for 28 days curing.
Table- III: Experimental test results

\begin{tabular}{|c|c|c|c|c|}
\hline Test & $\begin{array}{l}\text { Age of } \\
\text { Curing } \\
\text { (days) }\end{array}$ & $\mathrm{CC}$ & FCM 1 & FCM 2 \\
\hline Slump (mm) & - & 133 & 195 & 223 \\
\hline \multirow{2}{*}{$\begin{array}{l}\text { Density } \\
\left(\mathrm{kg} / \mathrm{m}^{3}\right)\end{array}$} & 7 & 2321 & 2001 & 1803 \\
\hline & 28 & 2450 & 2107 & 1911 \\
\hline \multirow{2}{*}{$\begin{array}{l}\text { Compressive } \\
\text { Strength }\left(\mathrm{N} / \mathbf{m m}^{2}\right)\end{array}$} & 7 & 22.29 & 13.73 & 16.43 \\
\hline & 28 & 33.17 & 20.49 & 25.56 \\
\hline \multirow{2}{*}{$\begin{array}{l}\text { Split Tensile } \\
\text { Strength }\left(\mathrm{N} / \mathbf{m m}^{2}\right)\end{array}$} & 7 & 1.59 & 1.40 & 1.48 \\
\hline & 28 & 2.38 & 2.09 & 2.21 \\
\hline \multirow{2}{*}{$\begin{array}{l}\text { Flexural } \\
\text { Strength }\left(\mathbf{N} / \mathbf{m m}^{2}\right)\end{array}$} & 7 & 3.92 & 1.78 & 2.12 \\
\hline & 28 & 4.53 & 3.12 & 3.78 \\
\hline \multirow{2}{*}{$\begin{array}{l}\text { Water } \\
\text { Absorption (\%) }\end{array}$} & 7 & 9.15 & 13.26 & 11.80 \\
\hline & 28 & 7.96 & 11.79 & 10.22 \\
\hline
\end{tabular}

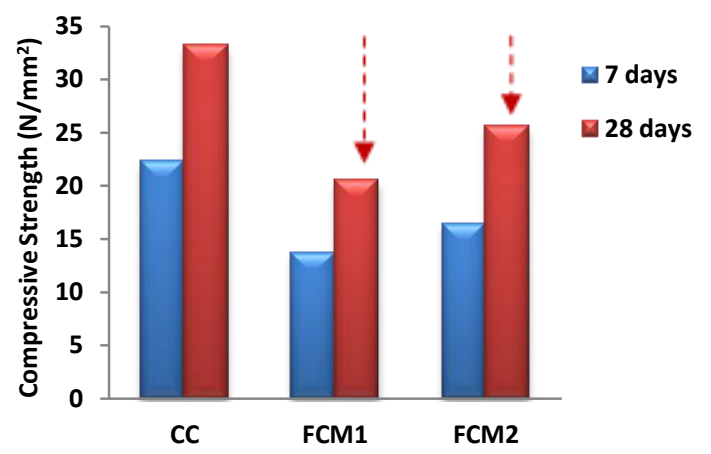

Fig. 1.Compressive strength for Foam Concrete Mixes

From figure 1, it is understood that the foam concrete mix (FCM1) without fly ash, the compressive strength has got reduction of $39 \%$ than the controlled specimen. The reason behind can be the minimum composition of the filler material. In the foam concrete mix, by the addition of mineral admixture such as flyash, the compressive strength has got some advantage of enhancing $20 \%$. These fine particles (flyash) will occupy the voids and there by good bonding can be achieved in the concrete. These foam concrete mixes (FCM2) have achieved the compressive strength of about 80 $\%$ to $85 \%$ of M30 grade with the maximum reduction of self weight around by $23 \%$. In considering the reduction of self weight and high workable point of view, this foam concrete mix (FCM2) is better, since it has not compromised much of the compressive strength.

From figure 2, it is observed that there is not much deviation for the conventional concrete and foam concrete. The split tensile strength is $2.38 \mathrm{~N} / \mathrm{mm}^{2}, 2.09 \mathrm{~N} / \mathrm{mm}^{2}$ and $2.21 \mathrm{~N} / \mathrm{mm}^{2}$ for the conventional concrete, FCM1 and FCM2 respectively for the 28 days curing. The tensile strength difference is only $13 \%$ for the conventional concrete and FCM1. By considering flyash presence in the FCM2, the difference observed is least i.e $7 \%$.

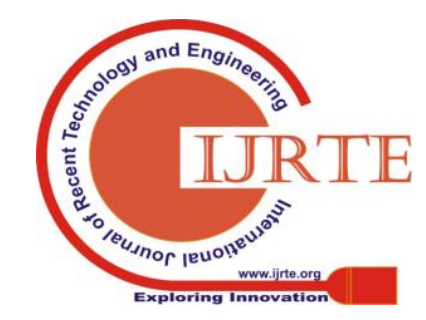




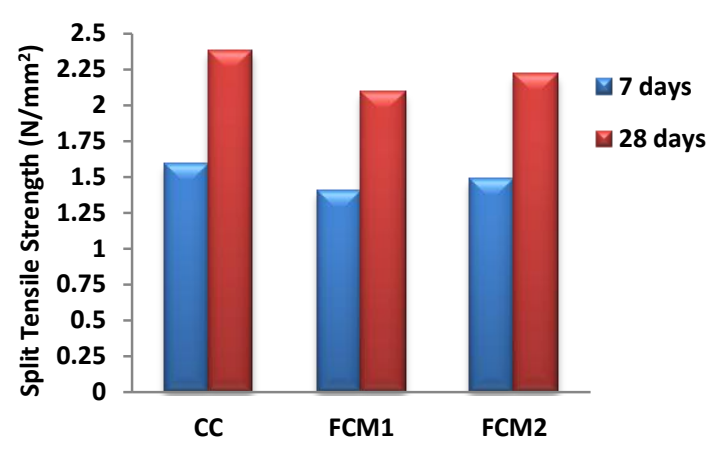

Fig. 2. Split tensile strength for Foam Concrete Mixes

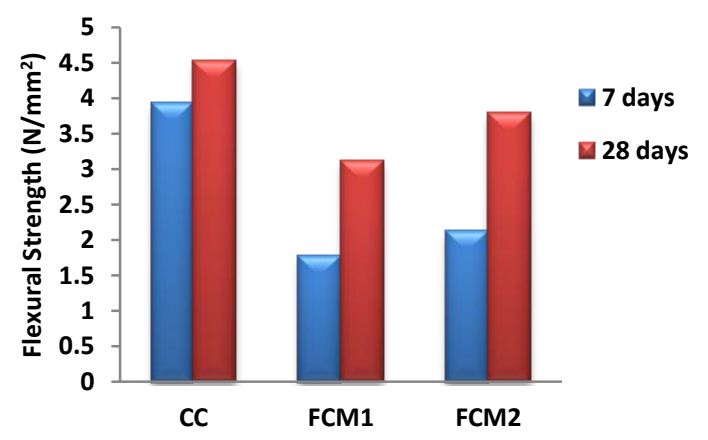

Fig. 3. Flexural strength for Foam Concrete Mixes

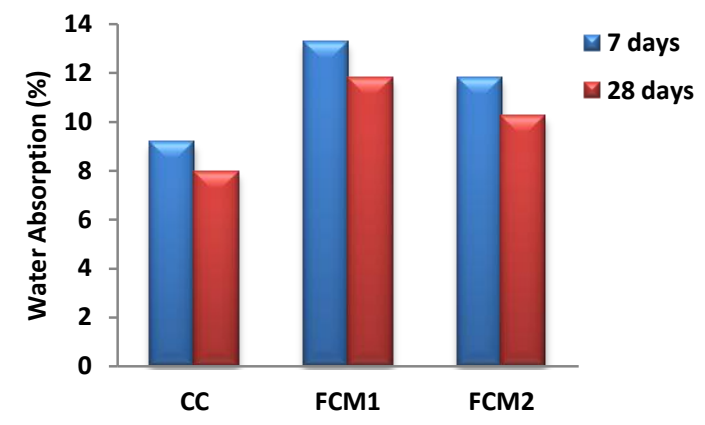

Fig. 4. Flexural strength for Foam Concrete Mixes

The conventional concrete has the flexural strength in 28 days is $4.53 \mathrm{~N} / \mathrm{mm}^{2}$ where as the foam concrete mix FCM1 and FCM2 has $3.12 \mathrm{~N} / \mathrm{mm}^{2}$ and $3.78 \mathrm{~N} / \mathrm{mm}^{2}$ respectively. By comparing conventional concrete and foam concrete mix FCM1 the flexural strength has the reduction of $30 \%$. In comparing with foam concrete mix FCM2, the reduction is around $16 \%$ as seen from figure 3. As theoretically, for a concrete the flexural strength is around $12 \%$ to $20 \%$ of the compressive strength. Here in this experimental study, the flexural strength of the conventional concrete is $14 \%$ of compressive strength and flexural strength of both foam concrete mixes will be around $15 \%$ of its compressive strength. This shows that there is a well correlation between the theoretical part and this experimental study. In the durability point of view, the water absorption rate of the conventional concrete is $7.96 \%$ where the foam concrete mix FCM1 and FCM2 has $11.79 \%$ and $10.22 \%$ respectively for the age of 28 days. For foam concrete mix FCM1, the water absorption rate is $33 \%$ higher than conventional concrete and for mix FCM2, the rate is around $22 \%$ higher than conventional concrete as seen figure 4 . The rate of water absorption is decreased around $13 \%$ for foam concrete mix FCM2 due to the influence of flyash. These finest particles will occupy the pores and voids of the concrete and thereby it participating in the gel formation along with other constituents of concrete. By this way, foam concrete mix FCM2 is impermeable than the mix FCM1. As in overall, the 7 days and 28 days behavior are almost same for both conventional concrete and foam concrete mixes. As age of curing days increased, all the characteristics related to strength and durability properties, are also got enhanced due to the hydration process.

\section{CONCLUSIONS}

1) Foam concrete shows more workable than conventional concrete. While further adding admixture flyash in to foam concrete, remarkable improvement is seen in the workability. Therefore the degree of workability is changed from medium to high.

2) Around $20 \%$, it is possible to reduce the self weight by the foam concrete and thereby the cost is optimized through some economical sections in the member design.

3) In foam concrete (FCM1), compressive strength achieved is around $61 \%$ of the conventional concrete. In order to enhance the strength aspects, flyash can be introduced in to the foam concrete (FCM2) and thereby the strength is increased upto $85 \%$ with the reduction of $23 \%$ density.

4) Water absorption rate of foam concrete is around $33 \%$ higher than conventional and foam concrete with flyash, the rate of water absorption is reduced to around $13 \%$.

5) Still the research on foam concrete is widely open in varying the percentage of foam, type of foam and type of admixtures to enhance the strength and durability properties.

\section{REFERENCES}

1. JonesM. R. and McCarthyA. "Preliminary views on the potential of foamed concrete as a structural material -Magazine of Concrete Research, 2005, 57, No. 1, February, 21-31

2. FahrizalZulkarnain, MahyuddinRamli "Performance and Characteristic Foamed Concrete Mix Design with silica fume for housing development -international journal of academic research Vol. 3. No. 2. March, 2011, Part IV".

3. M. A. O. Mydin and Y. C. Wang, "Mechanical properties of foamed concrete exposed to high temperatures," Construction and Building Materials, vol. 26, no. 1, pp. 638-654, 2012.

4. Y. M. Hunaiti, "Strength of composite sections with foamed and lightweight aggregate concrete," Journal of Materials in Civil Engineering, vol. 9, no. 2, pp. 58-61, 1997.

5. EE. P. Kearsley and P. J. Wainwright, "Ash content for optimum strength of foamed concrete," Cement and Concrete Research, vol. 32, no. 2, pp. 241-246,

6. X. J. Tan, W. Z. Chen, H. M. Tian, and J. P. Yuan, "Degradation characteristics of foamed concrete with lightweight aggregate and polypropylene fibre under freeze-thaw cycles," Magazine of Concrete Research, vol. 65, no. 12, pp. 720-730, 2013.

7. U. J. Alengaram, B. A. Al Muhit, M. Z. bin Jumaat, and M. L. Y. Jing, "A comparison of the thermal conductivity of oil palm shell foamed concrete with conventional materials," Materials and Design, vol. 51, pp. 522-529, 2013.

8. PL. Meyyappan, K.Kumaran, M.Gopalakrishnan and E. Harikrishnan (2018), "Effect of glass fibers, flyash and quarry ash on Strength and Durability Aspects of Concrete - An Experimental Study", IOP Conference Series: Material Science and Engineering, 
doi:10.1088/1757-899X/396/1/012001.

9. PL. Meyyappan, K.Kumaran, M.Gopalakrishnan and E. Harikrishnan (2018), "Experimental Investigation on the Effect of Silica fume and Pumice stone in Developing Light Weight Concrete", IOP Conference Series: Material Science and Engineering, doi:10.1088/1757-899X/561/1/012064.

10. PL. Meyyappan, P. Amuthakannan, R. Sutharsan and M. Ahamed Azik Ali (2019), "Utilization of M-Sand \& Basalt Fiber in Concrete: An Experimental Study on Strength and Durability Properties", IOP Conference Series: Material Science and Engineering, doi:10.1088/1757-899X/561/1/012035.

\section{AUTHORS PROFILE}

Dr. PL. Meyyappanhas completed his graduation and post-graduation from Bharathiyar University and Karunya University respectively. He completed his $\mathrm{PhD}$ from Kalasalingam University. He has 13 years of teaching experience. He has completed 2 sponsored research projects from TNSCST and published more than 25 papers in peer reviewed journals and conferences. He is a life member in ISTE, IEI, IGS, ISET, ISRS. He is serving as Editorial Board Member and Reviewer in various reputed Journals.

Mr. BharathBalji has completed his B.Tech in Civi Engineering in Kalasalingam Academy of Research and Education, Krishnankoil in the year 2018.. He is doing his M.Tech degree in SSN College of Engineering, Chennai. 